\title{
Analysis of Liquefied Petroleum Gas (LPG) Shortage in Ghana: A Case of the Ashanti Region
}

\author{
David Asamoah (Corresponding author) \\ Department of Information Systems and Decision Sciences, KNUST School of Business \\ Kwame Nkrumah University of Science \& Technology, Ghana \\ Tel: 233-24-454-2264, 233-20-350-4444Ｅ-mail: dasamoah.ksb@knust.edu.gh \\ Richard Amoakohene \\ Department of Information Systems and Decision Sciences, KNUST School of Business \\ Kwame Nkrumah University of Science \& Technology, Ghana
}

Tel: 233-24-351-2015

Ernest Adiwokor

Department of Information Systems and Decision Sciences, KNUST School of Business

Kwame Nkrumah University of Science \& Technology, Ghana

Tel: 233-26-109-5759_E-mail: ernestad1748@gmail.com

\author{
Received: August 2, 2012 \\ Accepted: September 4, 2012 \\ Online Published: September 12, 2012 \\ doi:10.5430/ijba.v3n5p89 \\ URL: http://dx.doi.org/10.5430/ijba.v3n5p89
}

\begin{abstract}
Liquefied Petroleum Gas (LPG) is increasingly becoming the preferred choice of fuel in the world. The increase in patronage could be attributed to its affordability, efficiency and environmental friendliness. Like other energy sources, there are challenges that impede the smooth supply of LPG resulting in shortage. Several factors are involved which ultimately affects the efficiency of the entire Supply Chain system. The perennial LPG shortage in Ghana is an uncomfortable experience that needs urgent attention. Therefore, the study seeks among others to investigate the magnitude of noted disruptions that contribute to the shortage of LPG and the extent to which the LPG usage categories influence the length and frequency of shortage. A survey methodology was deployed for a total of 35 LPG retailers and 120 consumers in the Ashanti Region of Ghana. Results of the study indicated that the Technical and Transportation disruption was ranked by retailers and consumers as major factors that disrupt the supply of LPG. Analysis carried out revealed that the frequency of LPG shortages experienced by consumers depends on the categories of usage, whilst the consumers' experiences of the duration for LPG shortage are rather independent on the categories of usage.
\end{abstract}

Keywords: Liquefied Petroleum Gas (LPG), Shortage, Disruptions, Ghana

\section{Introduction}

In recent decades, there is an increasing patronage of Liquefied Petroleum Gas (LPG) throughout the world. Subsequently, the supplies of LPG are growing to meet demand. In 1985, world supply was approximately 114 million tonnes and this was expected to increase to 240 million tonnes in 2005 (Purvin and Gertz, 2000). Like many other developing countries, the Government of Ghana has since the early 1990s been promoting the use of Liquefied Petroleum Gas. This was necessitated largely by the unreliable electricity supply and its attendant high tariffs and the depletion of forests as a result of the usage of biomass fuel. Marful-Sau (2009) attributed the unreliable electricity supply to low generating capacity, in the midst of increasing national demand. For instance, as a result of climate change, hydro-generation from the Akosombo plant fell from $1020 \mathrm{MW}$ to $300 \mathrm{MW}$ in the dry seasons (Ofosu-Ahenkora, 2009 cited in Marful-Sau, 2009). There is no doubt that the Ghana government LPG promotion 
campaign has yielded positive results with consumption of LPG increasing from 43502800 kilograms in 1999 to 220602979 kilograms in 2009, representing a percentage increase of 407 (NPA, 2010).

In Ghana, LPG is primarily used for cooking in households, commercial establishments and hotels. Some industries also use it as a source of fuel for their processes. Its use is also rapidly growing in the transport sector as a substitute fuel for premium. An adequate and reliable supply of LPG therefore plays a vital role in the sustainable development of the country. LPG is supplied to the market from both the local refinery and imports. However, domestic LPG production is limited and imports account for the vast majority of the total supply to the market. The Tema Oil Refinery (TOR) is responsible for all domestic supplies of LPG in Ghana and also handles all imports of LPG and refined products. Current refinery production of LPG is about 18000 tonnes per year, and net imports of approximately 22000 tonnes per year supplement domestic production to meet the total demand (NPA, 2010). Despite this production level, LPG shortage in the country is becoming a common phenomenon yearly. The supply of LPG in the country experiences disruptions which usually result in shortage of the fuel. This is manifested by long queues at Gas stations. The resultant economic and environmental losses of these disruptions are enormous. Riddalls et al. (2002) noted that the costly effects of disruptions are followed by increased lead-times, shortages, reductions in customer service levels and increase in varied costs. The continuous absence of LPG in the market would therefore be a recipe for both domestic and commercial users of the product to revert to the use of electricity, charcoal and firewood hence the need to ensure that disruptions in the supply of LPG are reduced to an acceptable minimum level. In addition to the problem of supply disruption, numerous researches have been conducted in the area of LPG within the country. Most of the papers focused on motivating Ghanaian citizenry to use LPG, with little or no evidence of researches examining the perennial LPG shortages in Ghana. Others also provided a more general supply chain mapping of LPG.

This current study is therefore positioned to assess among other objectives, the LPG shortage by examining the magnitude of noted disruptions that contribute to the shortage of LPG. It also probes further to gain a more realistic understanding of the nature and prevalence of risk (disruption) in the LPG supply chain and the interventions consumers use to contain shortages caused by these disruptions. The paper is divided into five sections; section one and two discusses the introduction and literature review respectively, section three discusses the methodology employed in the study, section four considers the analysis and discussion of results, and section five is recommendations and conclusions.

\section{Literature Review}

This section discusses the relevant theories and issues on the subject matter. The study focuses specifically on the supply and demand of LPG in Ghana, the supply chain of LPG, challenges (disruptions) and measures to mitigate these disruptions.

\subsection{Outlook on the Liquefied Petroleum Gas and Market}

Inkoom and Biney (2010) pointed that the world's energy needs are growing as a result of continued population increases, economic growth, and individual energy consumption. At the same time, emissions from fuel wood and fossil fuels- the main energy source for heating in homes and powering our economies, are contributing to climate change and affecting the air quality (WEC, 2005). LPG is the generic name for compressed hydrocarbon gases, typically butane and propane, a by-product of crude oil refining or from natural gas production. These gases have the unusual property of becoming liquid at room temperature when moderately compressed and reverting to gases when the pressure is sufficiently reduced. This gives them a considerable advantage over other fuels because they can be easily transported and stored in the liquid state. Inkoom and Biney (2010) stated that because it is clean, safe and very efficient in generating heat, the use of LPG represents major progress and contributes to quality of household life. LPG has a high energy content compared to most other oil products and burns readily in the presence of air (WLPGA, 2001).

\subsection{Supply and Demand of LPG in Ghana}

The growth in energy demand in Ghana has been driven by socio-economic and technical factors that have influenced each category of final energy use (Asamoah, 2009). However, the majority of Ghana's energy use is from biomass in the form of firewood and charcoal. The dependence on wood fuel has raised serious health and environmental concerns. For example, a study conducted in north of India found a correlation between incidence of respiratory ailments and the use of biomass-based fuels (Parikh et al., 2003). Ghana's reliance on wood fuel has also become a serious threat to the ecosystem of the country with almost $2 \%$ or 22000 hectares of forest depleted every year (UNDP, 2004). In lieu of the dire consequences of the use of biomass fuel, the consumption of LPG increased 
about five-folds from 45000 tonnes in the year 2000 to 220000 tonnes in 2009 but declined to 178000 tonnes in 2010 as shown in Figure 1. The Energy Commission of Ghana attributed this reduction in consumption in 2010 to the frequent shortages in supply.

\subsection{LPG Supply Chain}

Hugos (2003) defines supply chain as a network of facilities and distribution options that performs the functions of procurement of materials, transformation of these materials into intermediate and finished products, and the distribution of these finished products to customers. The network normally includes multiple suppliers, suppliers to suppliers, as well as multiple customers and customers' customers. In other words, the supply chain includes actors such as producers, distributors, retailers, customers and service providers (Chopra \& Meindl, 2003; Hugos, 2006). The LPG supply chain is a means through which LPG is delivered to consumers. LPG supply begins with the producers- the oil and gas industry. LPG marketers may be oil or gas company affiliates or independent businesses whose scale of operation may range from local to multi-national. LPG moves from the point of production to the ultimate user in a sophisticated transportation and distribution system (WLPGA, 2009).

A supply chain map could be developed to clearly illustrate the network of actors within LPG supply chain. Gardner and Copper (2003) describe Supply Chain maps as the visual representations of the flows of information, processes, and money between companies both upstream and downstream in the supply chain. These maps therefore must be done in coordination with management as a part of developing strategy. In addition, Miyake et al. (2010) states that SC Supply Chain maps result from the collection of different kinds of data which provides a holistic view that no one person has ever caught in its entirety.

\subsection{Supply Chain Disruptions}

Surajit and Dhalla (2010) noted that the success of supply chain is dictated by how well a company controls its supply base and mitigates supply bottlenecks and liabilities. Sheffi (2005) cited in Wang (2009) stated that there exists the high-possibility of the occurrence of disruptions within a supply chain and has discussed the effect these disruptions may have on the associated supply chain. Also, Handfield (2007) defines supply chain disruptions as major breakdowns in the production or distribution nodes that comprise a supply chain. Kleindorfer and Saad (2005) categorised disruption sources into three, namely operational contingencies, natural hazards and political instability. Operational contingencies include equipment malfunctions and systemic failures, abrupt discontinuity of supply, and other less severe forms of financial distress; and human-centred issues ranging from strikes to fraud. In addition, there are other conditions that create risks in a supply chain. These include distance from source, industry capacity, demand fluctuations and financial instability (MacKinnon, 2002; Lee et al., 1997; Singh, 1998; Larson and Kulchitsky, 1998 cited in Kleindorfer and Saad, 2005).

\subsection{Mitigating Supply Chain Disruptions}

Supply chain disruptions have dire consequences on business operations thus the need to manage them effectively. Schmitt and Singh (2009) discuss the importance of proactive planning to mitigate and recover from disruptions. To mitigate supply chain disruptions, companies can proactively assess risks and plan actions in advance of the disruptive events or they can discover risks by reactive strategies after disruptions occur and recover quickly from them (Zsidisin et al, 2004). Figure 2 is an elaboration from Tang (2006) showing the framework for mitigating supply chain risks.

\section{Research Methodology}

The survey strategy was employed to conduct this research because it is an effective technique to get opinions, attitudes and descriptions from respondents. Both primary and secondary data were used in conducting the study. Two questionnaires were designed: one for LPG consumers and the other for LPG retailers. Both closed and open-ended questions were used to design the questionnaires which were administered to address the objectives stated in the study.

Population for this study was all the LPG retailers and consumers in Ashanti Region, the largest city in Ghana after Accra. Population of consumers could not be taken into consideration because all consumers could not be accessed Therefore convenience sampling technique was used to select 120 consumers of LPG the study. However the population size of 35 retailers was used as provided by National Petroleum Authority (NPA).

In order to have a fair representation of the sample, consumers were selected from all LPG retailing stations. Selection of participants was based on those willing and able to dedicate at least 35 minutes. Each of the participants 
was contacted in person. A pilot study was conducted by pre-testing the questionnaire on 20 consumers of LPG, and it was meant for instrument validation and refinement.

\section{Data Presentation, Analysis and Discussion of Findings}

\subsection{LPG Supply Chain in Ghana}

The structure of LPG supply chain is shown in figure 3 based on the findings from the field and review of literature. Whilst the weak links depict very minimal or no interaction between supply chain actors, the strong links indicate a high degree of interaction between supply chain actors. The main actors in the supply chain of LPG include the consumers, retailers or dealers, Oil Marketing Companies (OMCs), and Tema Oil Refinery. LPG imports are combined with domestic production at TOR to supplement the LPG demand for Ghana. The product is then stored in bulk storage tanks at TOR with the capacity of about 6 400MT. Consumers with small cylinders either send their empty cylinders to retailers or have their cylinders picked by dealers to refill them. However, users with large volume cylinders are supplied with LPG after placing an order from OMCs. The retailers serve as main link between consumers and OMCs because OMCs are companies who have the license to procure and sell petroleum products to bulk customers and the general public through retail stations and reseller outlets. Established in 2005 under the Six Hundred and Ninety-First (691) Act of the Parliament of the Republic of Ghana (ACT 691), the NPA is the main statutory agency that regulates the petroleum downstream sector. The GSB, GNFS and EPA are other prominent agencies mentioned by the retailers interviewed as other regulators in the LPG industry. Most of the retailers interviewed were aware of the basic laws or requirements needed to set up an LPG filling station but did not share in the opinion that some laws affect their operations. Facilitators in the supply chain of LPG such as banks and insurance companies also play a crucial role in ensuring that actors in the supply chain have sound financial standings and protection against undesired happenings.

The researchers sought to find out from consumers the factors that contribute to the shortage of LPG in Ghana. The question required the respondents to rank the various factors on the scale of seven. Table 1 shows the descriptive statistics of the various factors. The statistics shows that technical disruption was highly rated, followed by financial, transportation, political, natural disaster and location.

Table 2 shows the descriptive statistics of retailers ranking by retailers of the various disruptions that contribute to the shortage of LPG. The descriptive statistics shows that, on average technical disruption was found to be highly rated with a mean of 3.677 , followed by the transportation disruption with a mean of 2.382 . Financial and natural disaster both had a mean of 2.294 whilst location had the least weight with a mean 1.559.

\subsection{Interventions to Control LPG Shortage}

Figure 4 and 5 shows the interventions used by retailers and consumers respectively in managing the shortage of LPG.

Figure 4 shows how retailers try to control or minimise the impact of LPG shortage by the use of specific supply chain interventions. As depicted in figure 4, retailers who order for the product from their suppliers early to ensure that they do not run out of LPG is represented by forty seven percent $(47 \%)$. Thirty two percent (32\%) of the respondents try to control or eliminate LPG shortages by the use of efficient transport system, sixteen percent (16\%) use safety stock whilst five (5\%) increase their storage capacities in order to store more of the product.

Figure 5 shows the supply chain interventions adopted by consumers to reduce or curb the impact of LPG shortage. Consumers ordering early from suppliers had the highest percentage of fifty two (52\%), the use of more than one storage container had thirty five (35\%), whilst the use of safety stock had the lowest percentage of thirteen (13\%).

The researchers use cross-tabulation method to see if category of usage will influence shortage frequency at 2 degrees of freedom, the p-value was $0.011<0.05$. The outcome therefore reveals that the usage category influences the frequency of LPG shortage per year. The Cramer's V statistics show the extent to which the LPG shortage frequency is related to the categories of usage. The results indicated a positive association with effect size of 0.273.

The researchers use cross-tabulation method to see if category of usage will influence shortage duration at 2 degrees of freedom, the p-value is $0.127>0.05$. Hence it proves a point that, duration the consumers will experience shortage is independent on the results of usage the consumers find themselves. The Cramer's V statistics show the extent to which the LPG shortage duration is related to the categories of usage. The results indicated a positive association with effect size of 0.185 .

\subsection{Discussion of Results}

The National Petroleum Authority attributed the shortage of LPG in the markets to four main constraints faced by TOR. These constraints are mainly identified within the LPG supply chain system. They are berth, pumping, storage 
and delivery constraints. This confirms Kleindorfer and Saad (2005) study that the capacity of a particular industry contributes to disruptions in the supply chain of that industry which result in the inability to supply the quantities demanded by purchasers. In this study, six main disruptions in the supply chain of LPG were identified and respondents were made to rank them. They are transportation, political, financial, location, natural disasters and technical disruptions. The study found out that technical disruption was ranked highest among the consumers. This confirmed the opinion expressed by retailers because technical disruption was also considered the major disruption affecting the LPG supply chain. These technical disruptions as noted by Kleindorfer and Saad (2005) result from equipment malfunctions and systemic failures, abrupt discontinuity of supply, and other human-centred issues ranging from strikes to fraud. Transportation was considered the second most predominant supply chain disruption among the retailers. This could be attributed to long distance from the source of LPG, which adds uncertainty to supply continuity through longer lead times. Financial and natural happenings had equal weights whilst location and political disruptions were ranked as the lowest. However, consumers ranked financial, transportation, political, location and natural happenings as the second, third, fourth, fifth and sixth most significant disruptions in the supply chain of LPG respectively.

The study also found out that most consumers and retailers had put in place certain measures to help reduce or control the effect of shortages caused by these disruptions. The most prominent strategy adopted by both retailers and consumers to reduce LPG shortages is by placing order for the product early. However, this is dependent on the availability of LPG from suppliers; because no matter how early the product is ordered, it would be seemingly impossible to be supplied when the shortage is from suppliers. Whilst efficient transportation system was the second most prominent strategy to reduce LPG shortage impact amongst retailers, the use of more than one storage container was found to be the second most common strategy that has been adopted by consumers to control the shortage. Increasing the storage capacity of containers by retailers was found to be the least adopted strategy to curtail LPG shortage. This could be attributed to the regulation by NPA that the capacity of storage facilities that can be used by a retailer is dependent on the size of land used for a refilling station. In order to ensure that they do not experience stock-outs, it was also found out that the use of safety stock has been engaged by both retailers and consumers. The erratic supply of LPG by suppliers could be one of the reasons why retailers and more especially consumers use safety stock.

Three main groups of LPG users were used for this study; domestic, commercial and domestic/commercial users. $80 \%$ of the total respondents interviewed were domestic users, $13.3 \%$ were commercial users whilst the remaining percentage was found to be both commercial and domestic users of LPG. Although, all users are affected when there is shortage of the product, the study revealed that the frequency of shortage of the product depends on the categories of usage the consumers find themselves. The Cramer's V statistics indicated a positive association with effect size of 0.273 to confirm that LPG shortage frequency is related to the categories of usage. The frequency of shortage in a year was found to be higher for commercial users than domestic users. This could be attributed to the rate at which they use LPG. $66.7 \%$ of domestic consumers revealed that they have experienced the shortage less than three times a year whilst the rest have experienced the shortage between four and eight times. On the part of commercial consumers, $68.8 \%$ of the respondents have experienced the shortage between four to eight times in a year while the remaining experienced the shortage for less than three times a year. This high shortage frequency could be attributed to either the use of small or inadequate storage containers.

The study also found out that how long consumers experience shortage of the product is independent of the user category. A higher percentage of domestic users experienced the shortage for a comparably shorter time than commercial users. $68.8 \%$ of commercial users interviewed experience the shortage for between 6 and 10 weeks compared to the $47.9 \%$ of domestic users who experience the shortage for the same duration. This result shows how severe LPG shortage could be in the country because users could live without LPG for over a month.

\section{Conclusions and Recommendation}

The study recommends that actors in the supply chain should be made fully aware of their responsibilities in order to take the needed initiatives that will result in positive impacts on the supply chain. This could be achieved through the establishment and management of relationships and risks or bottlenecks within the supply chain of LPG. A major conclusion that could be drawn from this research is that the main producer and supplier of LPG, TOR, contributes extensively to the shortage of LPG in the market due to infrastructural limitations. It is thus recommended that the government secures private sector participation in the mid-stream refining segment. Private sector investors must be encouraged by the government to make long-term investments in developing the storage and transmission capacity of LPG within the country. 
The fact that LPG shortage is not experienced everyday throughout the year means that there comes a time when supply of the product either exceeds or equilibrates demand. This invariably means that a constant supply to the market by TOR at its current capacity is enough to meet the demand of LPG. It is thus recommended that TOR ensures that vessels with LPG berth weekly to deliver products so as to regulate the shortfall from TOR's production. This will increase the local stock levels for LPG. Also, the current system whereby consumers send their empty containers to refilling stations to fill them could be improved upon. Consumers should have the option of purchasing already filled cylinders at shops whiles they exchange their empty containers. This is practised in other countries like Cameroon and Senegal where marketing companies own the cylinders (similar to the soft drinks distribution system that exists in Ghana). When this system is adopted, it would indirectly increase the overall storage capacity of LPG in the country; which will consequently reduce the storage constraints associated with storage at TOR.

Although the supply of LPG is faced with many challenges, it is recommended that whiles the government is promoting the continuous usage of LPG as a clean fuel to save our forests, it equally campaigns for the conservation and judicious usage of the product by consumers.

LPG as a source of fuel is increasingly becoming popular among Ghanaians. This is because it is affordable, clean and efficient in the distribution of goods and services. The increase in consumption of LPG would not end anytime soon, it is therefore imperative on all stakeholders to ensure that the excessive demand of the product does not result in shortages. As such there is the need for the continuous supply and sustainability of LPG to every area of the populace. There is no doubt that improvements in the supply chain of LPG would ensure that the product is always available for consumers.

\section{References}

Asamoah, E. (2009). Meeting the demand for petroleum products in year 2020: What is the road map for Ghana? [Online] Available: www.dundee.ac.uk/cepmlp/gateway/files (17 September, 2011)

Chopra, S., \& Meindl, P. (2003). Supply Chain Management: Strategy, Planning and Operation. USA. Prentice Hall. Energy Commission. (2011). Energy supply and demand outlook for Ghana. [Online] Available: http://www.energycom.gov.gh (19 September, 2011)

Gardner, J.T., \& Cooper, M.C. (2003). Strategic supply chain mapping approaches. Journal of Business Logistics, 24(2), 37-64.

Handfield R. (2007). Reducing the impact of disruptions in the supply chain: a managerial framework based on observations from multiple executives. Cary, NC, USA. SAS Institute Inc.

Hugos, M. (2003). Basic concepts of supply chain management. Essentials of Supply Chain Management. John Wiley \& Sons.

Hugos, M. (2006). Essentials of Supply Chain Management. John Wiley \& Sons, Inc.

Inkoom, D.K.B., \& Biney, B.S. (2010). The potential of liquefied petroleum gas (LPG) as a viable energy option for the industrial sector in Ghana. Journal of Sustainable Development in Africa, 12(6), 34-61.

Kleindorfer, P., \& Saad, G. (2005). Managing Disruption risks in supply chains. Production and Operations Management, 14(1), 53-68.

Marful-Sau, S. (2009). Security of electricity supply in Ghana: can it be achieved through privatisation and liberalisation policies? [Online] Available: $w$ ww.dundee.ac.uk/cepmlp/gateway/files.php (12 September, 2011)

Miyake, D. I., Junior, A. S. T., \& Favaro, C. (2010). Supply chain mapping initiatives in the Brazilian automotive industry: challenges and opportunities. Journal of Operations and Supply Chain Management, 3(1), 79-97.

National Petroleum Authority. (2010). Detailed statistics of petrol consumption. [Online] Available: http://www.npa.gov.gh/npa_new/Downloads (3 November, 2011)

Parikh, J., \& et al. (2003). Cooking with biofuels: risk factors affecting health impact on rural women. Special article in Economic and Political Weekly, XXXVIII(26), June 28-July 4, 2681-2692.

Purvin, \& Gertz. (2000). Continued LPG demand growth changes historical trade patterns. Oil \& Gas Journal. [Online] Available: www.purvingertz.com

Riddalls C., \& et al. (2002). Production-inventory system controller design and supply chain dynamics. International Journal of Systems Science, 33(3), 181-196. 
Schmitt, A. J., \& Singh M. (2009). Quantifying supply chain disruption risk using Monte Carlo and discrete-event simulation. Published in Proceeding WSC '09 Winter Simulation Conference.

Surajit R., \& Dhalla R.S. (2010). Management of supply chain in petroleum corporations in India. Proceedings of the 2010 International Conference on Industrial Engineering and Operations Management. Dhaka, Bangladesh.

Tang, C.S. (2006). Robust strategies for mitigating supply chain disruptions. International Journal of Logistics, 9(1), $33-45$.

UNDP. (2004). Liquefied Petroleum Gas (LPG): substitution for wood fuel in Ghana-opportunities and challenges.

Infolink No. 1. UNDP Energy and Environment Practice. [Online] Available: www.undp.org/surfwa/docs/newsletter2

Wang, C. (2009). The study of supply chain facilities and their interconnection with critical civil infrastructure systems. [Online] Available: www.ce.udel.edu/UTC/Publications

WEC, World Energy Council. (2005). Statement on delivering sustainability: challenges and opportunities for the energy industry. [Online] Available: www.worldenergy.org (8 November, 2011)

WLPGA. (2001). West Africa LPG market development study. [Online] Available: www.worldgas.com/mainpages/publications/publications.php (5 September, 2011)

WLPGA. (2009). LP Gas exceptional energy. [Online] Available: www.worldlpgas.com/resources/publications (1 November 2011)

Zsidisin, G., \& et al. (2004). An analysis of supply risk assessment techniques. International Journal Physical Distribution Logistics Management, 34, 397-413.

Table 1. LPG supply chain disruptions ranking by consumers

\begin{tabular}{llll}
\hline Variables & & Std. Deviation & Std. Error Mean \\
& Mean & & \\
\hline Transportation & 3.017 & 0.978 & 0.090 \\
Political & 2.737 & 1.229 & 0.113 \\
Financial & 3.110 & 1.266 & 0.117 \\
Location & 2.231 & 0.971 & 0.090 \\
Natural Disasters & 2.322 & 1.045 & 0.096 \\
Technical & 4.314 & 1.182 & 0.109 \\
\hline
\end{tabular}

Source: Authors' Fieldwork, 2012

Table 2. LPG supply chain disruptions ranking by retailers

\begin{tabular}{|c|c|c|c|c|c|c|c|c|}
\hline \multicolumn{9}{|c|}{ Retailers Descriptive Statistics } \\
\hline & $\begin{array}{l}\text { Mean } \\
\text { Statistic }\end{array}$ & $\begin{array}{l}\text { Std. } \\
\text { Error }\end{array}$ & $\begin{array}{l}\text { Standard } \\
\text { deviation } \\
\text { Statistic } \\
\end{array}$ & $\begin{array}{l}\text { Variance } \\
\text { Statistic }\end{array}$ & $\begin{array}{l}\text { Skewness } \\
\text { Statistic }\end{array}$ & $\begin{array}{l}\text { Std. } \\
\text { Error }\end{array}$ & $\begin{array}{l}\text { Kurtosis } \\
\text { Statistic }\end{array}$ & $\begin{array}{l}\text { Std. } \\
\text { Error }\end{array}$ \\
\hline Transportation & 2.382 & 0.120 & 0.697 & 0.486 & 0.448 & 0.403 & 0.251 & 0.788 \\
\hline Political & 1.471 & 0.114 & 0.662 & 0.439 & 1.112 & 0.403 & 0.153 & 0.788 \\
\hline Financial & 2.294 & 0.166 & 0.970 & 0.941 & 0.837 & 0.403 & 0.716 & 0.788 \\
\hline Location & 1.559 & 0.096 & 0.561 & 0.315 & 0.303 & 0.403 & -0.900 & 0.788 \\
\hline Natural Disaster & 2.294 & 0.155 & 0.906 & 0.820 & 0.662 & 0.403 & 1.127 & 0.788 \\
\hline Technical & 3.677 & 0.167 & 0.976 & 0.953 & 0.300 & 0.403 & -0.326 & 0.788 \\
\hline
\end{tabular}

Source: Authors' Fieldwork, 2012 
Table 3. Chi-square analysis of LPG shortage frequency and category of usage

\begin{tabular}{|c|c|c|c|c|c|}
\hline \multirow[t]{2}{*}{ Usage category } & \multirow[t]{2}{*}{$\mathrm{n}$} & \multicolumn{2}{|c|}{$\begin{array}{l}\text { Frequency of LPG shortage per } \\
\text { year }\end{array}$} & \multirow[t]{2}{*}{$x^{2}$} & \multirow[t]{2}{*}{ P-value } \\
\hline & & $<3$ times & 4-8 times & & \\
\hline Domestic & 96 & 64 & 32 & \multirow{4}{*}{8.852} & \multirow{4}{*}{0.011} \\
\hline Commercial & 16 & 5 & 11 & & \\
\hline Domestic \& Commercial & 8 & 3 & 5 & & \\
\hline Total & 120 & 72 & 48 & & \\
\hline
\end{tabular}

Source: Authors' Fieldwork, 2012

Table 4. Chi-square analysis of LPG shortage duration and category of usage

\begin{tabular}{llllll}
\hline \multirow{2}{*}{ Usage category } & $\mathrm{n}$ & \multicolumn{2}{c}{ Length of shortage } & \multirow{2}{*}{$x^{2}$} & P-value \\
\cline { 3 - 5 } Domestic & 96 & 50 & $1-5$ weeks & 6 -10 weeks & \\
Commercial & 16 & 5 & 11 & 4.127 & 0.127 \\
Domestic \& Commercial & 8 & 2 & 6 & \\
Total & 120 & 57 & 63 & \\
\hline
\end{tabular}

Source: Authors' Fieldwork, 2012

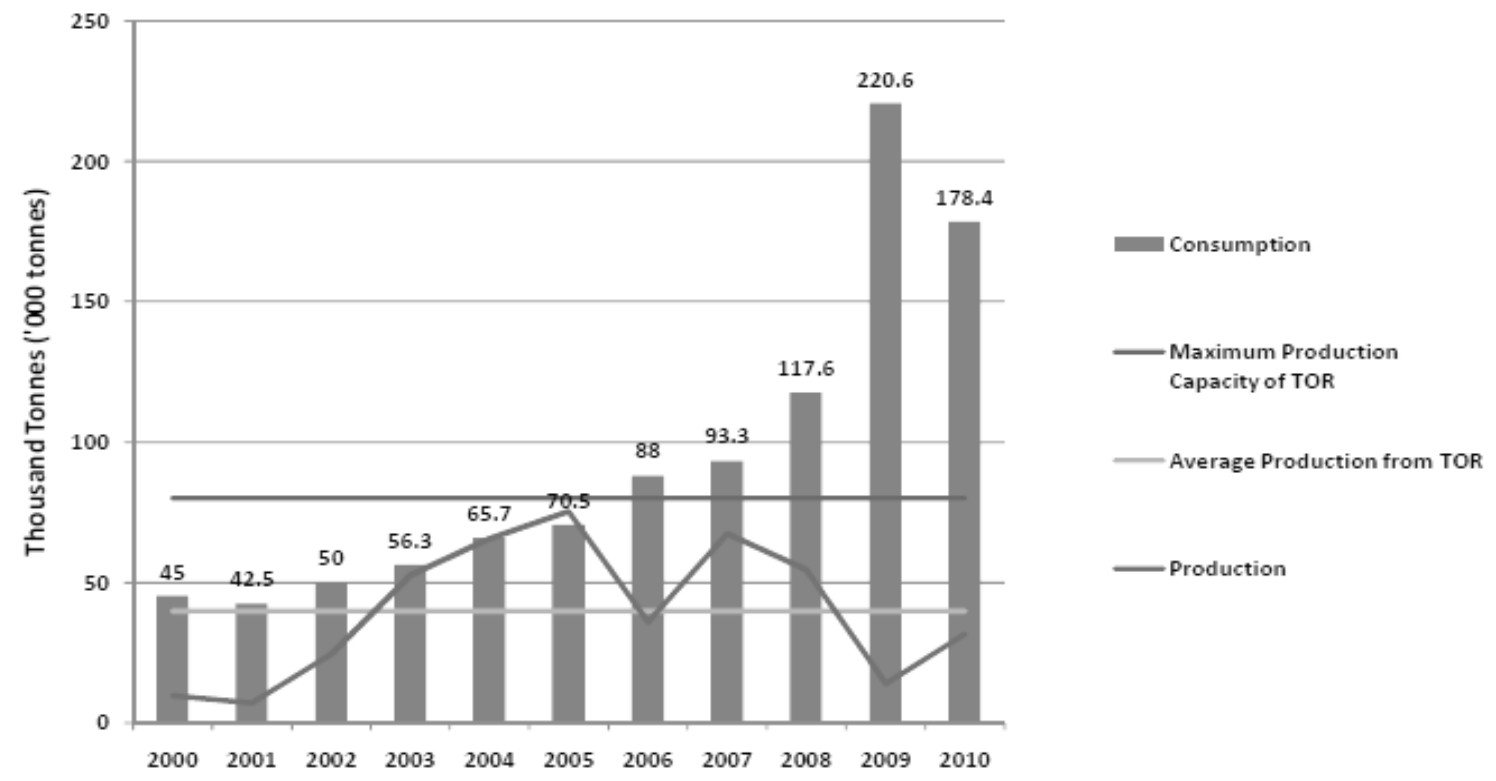

Figure 1. LPG production and consumption in Ghana

Source: Energy Commission of Ghana, 2011 


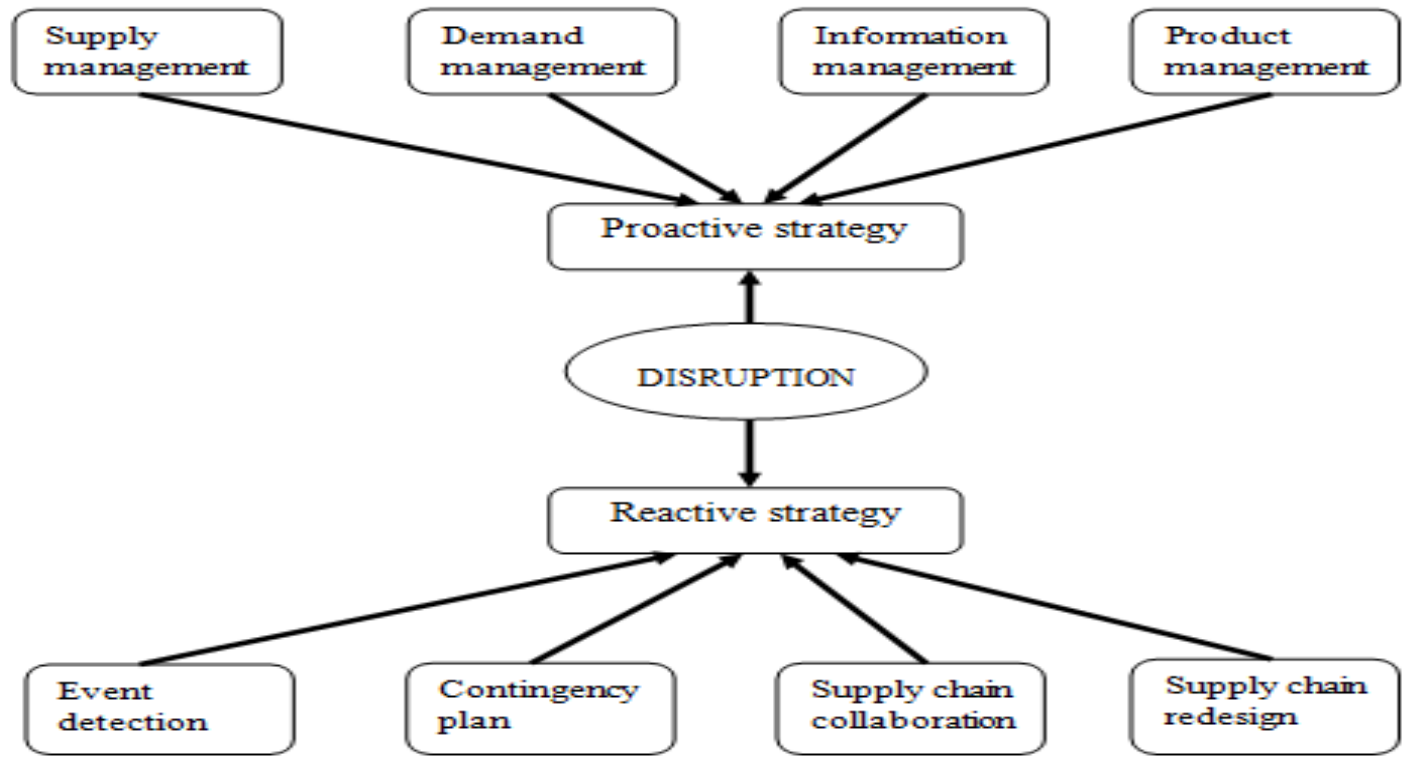

Figure 2. Framework for mitigating supply chain risks

Source: Tang, 2006

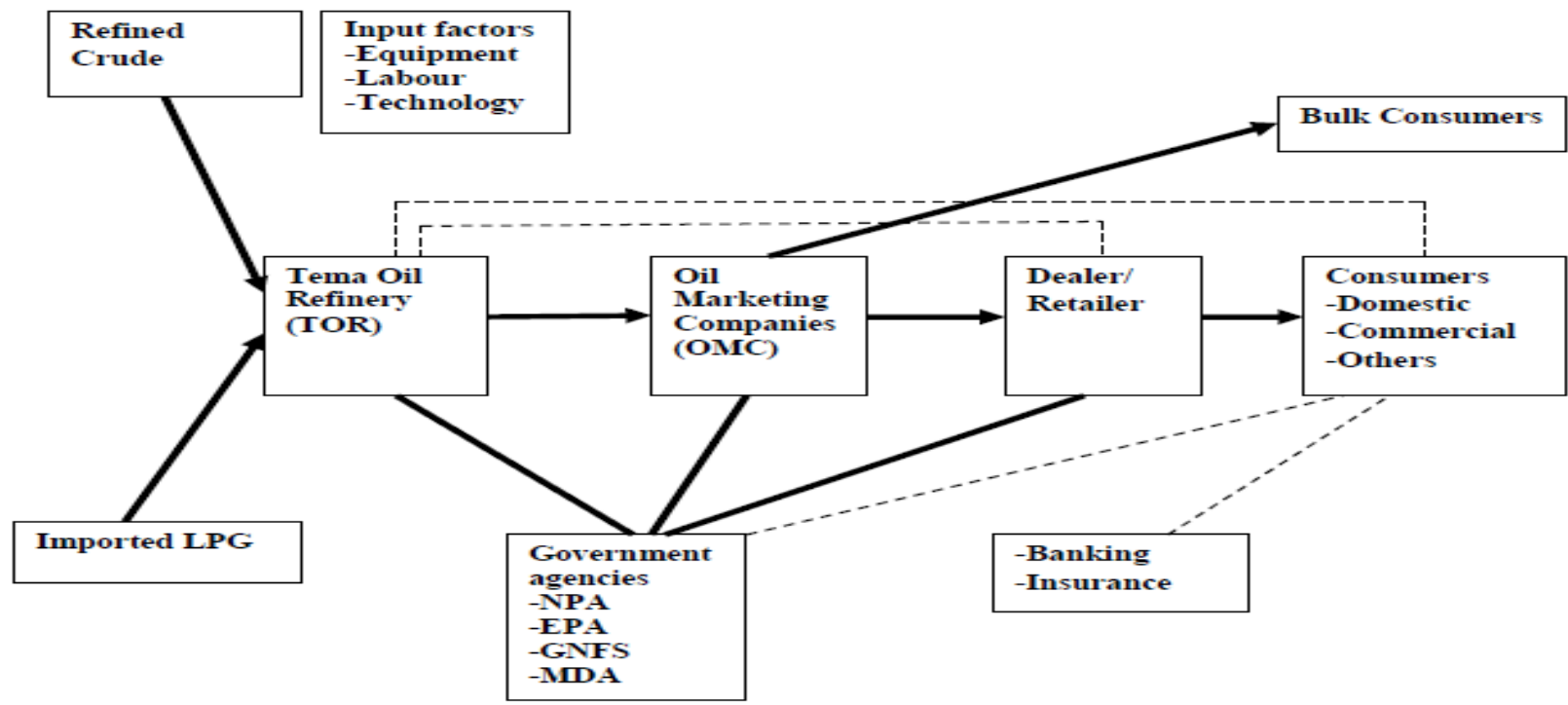

Strong Link

Weak Link

Figure 3. Structure and mapping of LPG supply chain

Source: Authors' Construct, 2012 


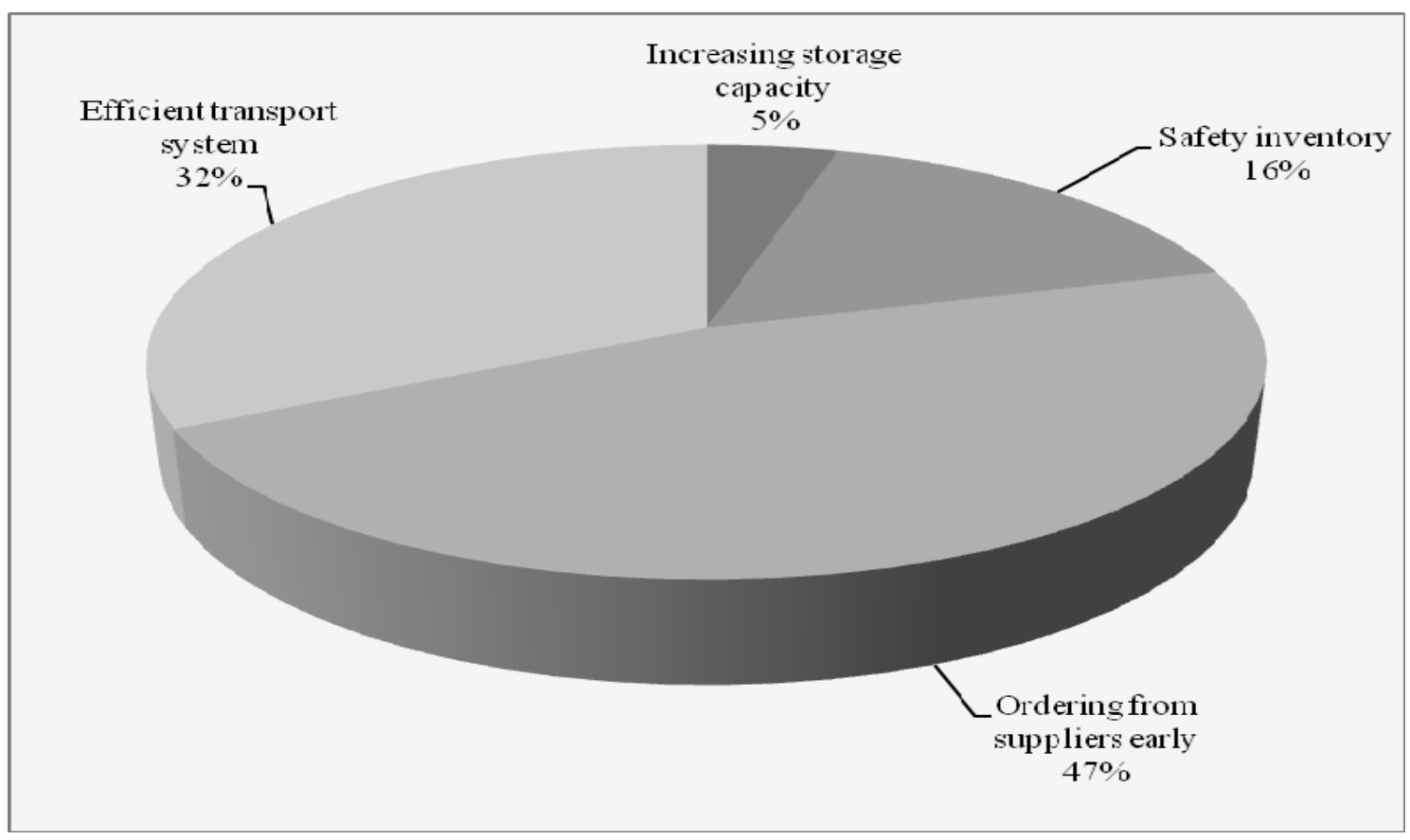

Figure 4. Interventions to Reduce impact of LPG disruptions by retailers

Source: Authors' field survey, 2012

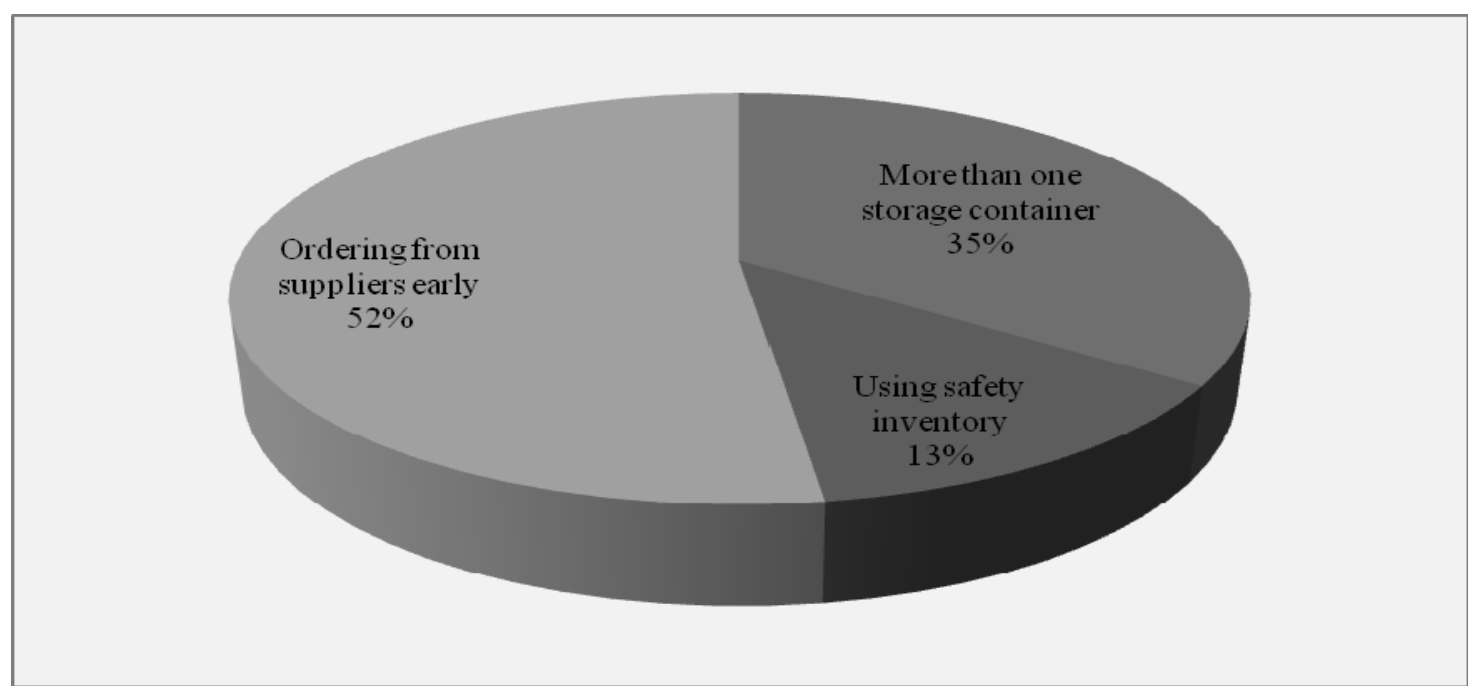

Figure 5. Interventions to reduce impact of LPG disruptions by consumers

Source: Authors' field survey, 2012 